Version of Record: https://www.sciencedirect.com/science/article/pii/S0031942219310623

Manuscript_f0c4c5fdf33e362d0f7d677025899ddc

\title{
Canopy isotopic investigation reveals different water uptake dynamics of maples and oaks
}

Matthew Lanning ${ }^{1}$, Lixin Wang ${ }^{1 *}$, Michael Benson ${ }^{2}$, Quan Zhang ${ }^{3}$, Kimberly A. Novick ${ }^{2}$

1

Department of Earth Science, Indiana University-Purdue University Indianapolis, 723 West Michigan Street, Indianapolis, IN 46202, USA

2

School of Public and Environmental Affairs, Indiana University Bloomington, 1315 East Tenth Street, Bloomington, IN 47405, USA

3

State Key Laboratory of Water Resources and Hydropower Engineering Science, Wuhan University, Wuhan 430072, China

* Correspondence to:

Lixin Wang (lxwang@iupui.edu)

Department of Earth Sciences

Indiana University-Purdue University Indianapolis

Indianapolis, IN 46202, USA

Office phone number: $317-274-7764$

This is the author's manuscript of the article published in final edited form as:

Lanning, M., Wang, L., Benson, M., Zhang, Q., \& Novick, K. A. (2020). Canopy isotopic investigation reveals different water uptake dynamics of maples and oaks. Phytochemistry, 175, 112389. https://doi.org/10.1016/j.phytochem.2020.112389 
Graphical Abstract:

\section{Acer sacharrum}

The water source accessed by maples may be dependent on new precipitation and merterological factors.

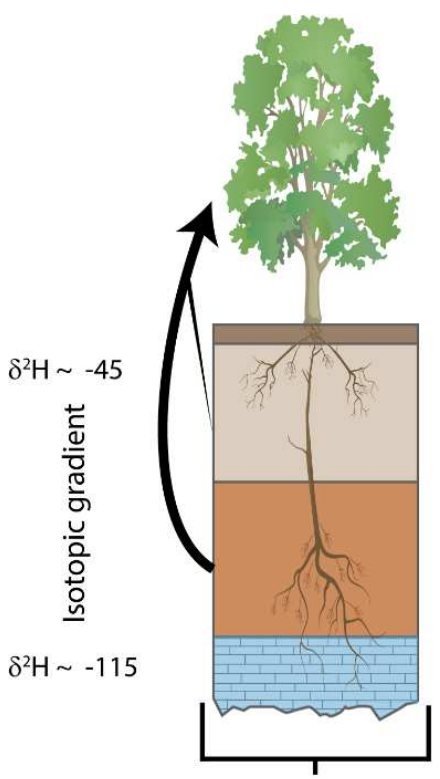

Deep water source utilization was previously uassociated with maples.

Deep water can be utilized over shallow moisture sources if the vapor pressure deficit is suffeciently high.

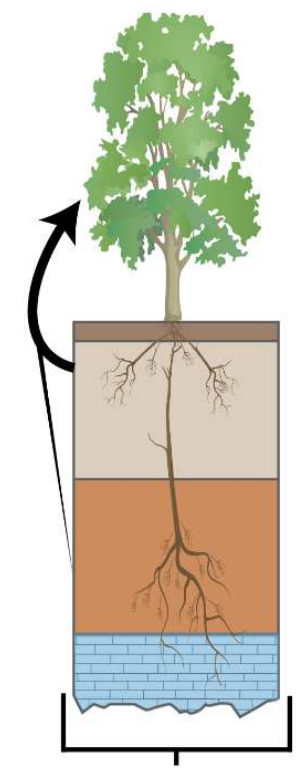

Shallow water utilization comes days after precipitation event which indicates maples use the new water once it reaches the roots. It is utilized even

if deep moisture is avalible.

\section{Quercus alba}

Oaks utilize only deep water sources and do not switch due to new precipitation or high VPD.

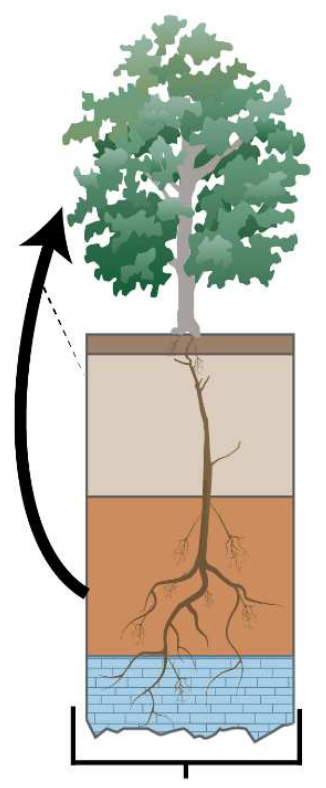

Daily isotope signature of the oaks reflects a deeper water pool and is not distingushable from the deep water source utilized by the maples. 


\begin{abstract}
:
Variations in drought responses exhibited by cohabiting tree species such as Acer sacharrum and Quercus alba have often been attributed to differences in rooting depth or water accessibility. A. sacharrum is thought to be a shallow rooted species, and is assumed to not have access to the deep and stable water resources available to $Q$. alba. As such, A. sacharrum conserves water by minimizing stomatal conductance under drought conditions whereas $Q$. alba does not. However, detailed records of sufficient temporal resolution which integrate water accessibility, meteorological drivers, and leaf level parameters (e.g., photosynthesis, stomatal conductance) are lacking, making such assumptions-though plausiblelargely untested. In this study, we investigated the water accessibility of both maples (A. sacharrum) and oaks $(Q$. alba) during the late growing season using novel canopy stable isotope measurements. Our results showed that maples can draw from the same water pool as cohabitating oaks, but can also switch to a shallow water source in response to available moisture in the shallow soil profile. We also found that maples tended to use a deep water source under high vapor pressure deficit even when shallow soil water was available. On the other hand, oaks had consistent deep water access during our study period. It is noted that our measurements do not cover the whole growing season and should be extrapolated with caution. Such findings indicate that differences in leaf functions during drought between maples and oaks may be due to both soil water accessibility and atmospheric water demand.
\end{abstract}

Keywords: conductance, drought, ecohydrology, stable isotope, stomata, transpiration

\title{
1. Introduction
}

Plants are responsible for movement of most terrestrial precipitation back into the atmosphere through transpiration (Jasechko et al., 2013; Schlesinger and Jasechko, 2014; Wang et al., 2014), making studies that link small scale stomatal processes and the larger forest system at the forefront of water resources research (Lanning et al., 2019). Understanding forest water use and tree accessible water resources will be invaluable for best forest management practices and for better predicting the responses of forests to global environmental changes.

At the leaf level, plants display different degrees of stomatal control under drought conditions (Klein, 2014; Martinez-Vilalta et al., 2014; Oren et al., 1999; Tardieu et al., 1996). Some tend to conserve water resources by reducing stomatal conductance thus limiting transpiration under conditions where soil moisture is low or atmospheric demand (vapor pressure deficit; VPD) is high, whereas others do this to a markedly less extent and maintain higher carbon fixation as a result (Roman et al., 2015; Tardieu et al., 1996; Yi et al., 2017). Opportunistic studies at different spatial scales during the Midwestern drought in 2012 (largest regional drought since 1933) at the United States Morgan Monroe State Forest flux tower 
(US-MMS; Martinsville, IN) contextualized the distinct behaviors of these species. Roman et al., 2015 observed that under drought conditions maples (Acer sacharrum) took up less $\mathrm{CO}_{2}$ (40\% reduction) as a consequence of their reduced stomatal conductance $\left(\mathrm{g}_{\mathrm{s}}\right)$, whereas oaks (Quercus alba and rubra) only experienced a 6\% reduction in photosynthesis (A) (Roman et al., 2015). Additionally, researchers at USMMS found that oak sap flux was unaffected by drought conditions, but maple sap flux reduced significantly (Yi et al., 2017). Studies at other sites corroborate these observations, also observing a distinct response to drought between these species (Matheny et al., 2016; Thomsen et al., 2013).

Despite unique drought response patterns, the environmental link explaining why oaks can maintain such high stomatal conductance in adverse conditions while maples cannot is still lacking. The most prominent line of reasoning is that species of Quercus are often deeply rooted (Abrams, 1990), and likely rely on a more stable water resource than maples, allowing them to buffer their response to drought conditions. But such an argument has not been experimentally tested. Stable isotopologues of water (e.g., ${ }^{1} \mathrm{H}^{2} \mathrm{H}^{16} \mathrm{O},{ }^{1} \mathrm{H}^{1} \mathrm{H}^{18} \mathrm{O}$ ) are uniquely powerful environmental tracers and have been widely used to identify the origins and movement of water through the hydrological cycle (Bowen and Wilkinson, 2002; Dawson and Ehleringer, 1993; Kaseke et al., 2017, 2016; Tian et al., 2018; Wang et al., 2012; Zhao et al., 2012). Subsurface waters (e.g., soil water, groundwater) have isotopically unique signatures imparted by the physical processes the water experiences as it moves through the hydrological cycle (Zimmermann et al., 1967). The stable isotope composition of hydrogen and oxygen is defined using delta notation as follows:

$$
\delta(\%)=\left(\frac{R}{R_{s t d}}-1\right) \times 1000
$$

where $\mathrm{R}$ is the ratio of ${ }^{2} \mathrm{H} /{ }^{1} \mathrm{H}$ or ${ }^{18} \mathrm{O} /{ }^{16} \mathrm{O}$ in the sample and $\mathrm{R}_{\text {std }}$ is the same ratio in the standard. The top of the soil column is typically dominated by more enriched waters (higher $\delta^{2} \mathrm{H}$ ) during the growing season due to precipitation and evaporation. Precipitation is isotopically enriched compared to the moisture from which it formed, so as it falls on the land surface the top of the soil column is inundated with an enriched signature. This is compounded by the kinetic fractionation of soil water during the process of evaporation (Zimmermann et al., 1967), leading to an overall enriched signature. Conversely, the lower portions of the soil column have more depleted signatures and are typically more stable. As precipitation percolates through the soil column it interacts with charged soil particles. This interaction causes kinetic fractionation of the mobile water as the heavier isotopologues take longer to disengage from soil particles than the lighter isotopologues do, causing the bottom of the soil profile to be isotopically depleted relative to the top (Oerter et al., 2014).

The isotopic signature of plant transpiration is a non-fractionated product of the source waters of the plant (White et al., 1985) and has been used to track the water uptake depth or source of trees (Gaines 
et al., 2016; Matheny et al., 2016). Currently, the most common way to approximate $\delta_{\mathrm{T}}$ for plants is by extracting the water from a xylem sample (e.g., West et al., 2006). While such methods are useful, to integrate measurements of leaf level parameters (e.g., photosynthesis, stomatal conductance) that vary on the order of minutes or less with changes in plant water sources across a day, a much finer and more direct measurement of $\delta_{\mathrm{T}}$ is required (Wang et al., 2012). Wang et al. (2012) describe a method which measures $\delta_{\mathrm{T}}$ effectively by plumbing plant transpiration directly into an isotope analyzer, which accurately measures the variability in $\delta_{\mathrm{T}}$ at fine sampling resolution. For shorter plants (e.g., row crops) this is logistically simple (Lu et al., 2017). However, in forested ecosystems where plants can be greater than $40 \mathrm{~m}$ tall, heavy machinery is required to transport the equipment necessary to the top of the canopy (Figure 1). Logistically this added necessity can reduce the number of days sampling can occur, but allows for measurements on the time scale necessary to resolve fine changes in leaf and ecosystem properties.

Based on isotopes, there is evidence that oaks primarily take from deeper water sources than maples when they co-exist (Matheny et al., 2016). However, there is also substantial variation in isotope signals for maples and oaks reported over the growing season (Matheny et al., 2016), possibly indicating that maples may utilize both shallow and deep water sources. An investigation into shared access of a deep water pool for maples and oak has not been done and the mechanisms, consequences, and frequencies of such occurrences have not been explored.

In this study we investigated the temporal patterns of source water uptake for maples (Acer sacharrum) and oaks (Quercus alba) during the late growing season of 2017, utilizing a boom lift (reach of up to $\sim 45 \mathrm{~m}$ ) to access the forest canopy and directly measure the isotopic composition of maple and oak transpiration at the US-MMS flux tower site (Figure 1). US-MMS is within a secondary successional deciduous broadleaf forest and has a rich record of micrometeorological and soil moisture measurements as well as fluxes of water and $\mathrm{CO}_{2}$ since 1999 (Schmid et al., 2000; see Figure S1). Additionally, there have been multiple studies (e.g., Roman et al., 2015) which have contributed to a robust measurement record of our study species. Our main focus was to determine the water uptake depth for maples and oaks during the late growing season and determine the mechanisms of different water uptake depth utilization.

\section{Results and Discussion}

\subsection{Water status of the study period}

Soil water status on measurement days was fairly stable (Figure 2). Daily mean soil moisture in the upper $30 \mathrm{~cm}$ varied by $4.5 \%$ across the study period (median $=19.53 \%$ ), increasing episodically ( $\max$ $=26.9 \%$ ) in response to precipitation events, which were scattered across the study period (Figure 2). 
Considering soil water status at US-MMS since 1999 , such conditions were all below the $25^{\text {th }}$ percentile for the growing season $(27.91 \%)$, most below the $15^{\text {th }}$ percentile $(21.9 \%)$. VPD was low and stable across most measurement days (DOY 243, 248, 250 and 271), but rose substantially between DOY 250 and DOY 269 (Figure 2). On DOY 269, VPD was above the $95^{\text {th }}$ percentile $(1.58 \mathrm{kPa}$ ) of historical daily VPD observations at US-MMS (Figure 2). Otherwise, all daily VPD measurements were at or below the $70^{\text {th }}$ percentile (1.04 kPa). When considered together, most observation days were under fairly severe soil water stress, but normal atmospheric water stress. It should be noted that soil moisture was measured near our sampled trees, not directly within their rooting zone. So while the soil moisture data is a precise representation of water movement within the upper $30 \mathrm{~cm}$ of the soil column (see response to precipitation, Figure 2), it may not exactly reflect the soil moisture status of our measured trees. Data for the measurement year (2017) was provided by the US-MMS flux tower team. FLUXNET 2015 data product was used as historical data and to compute quantiles (Figure S1).

$2.2 \delta_{\mathrm{T}}$ reveals unique water uptake pattern for maples

Water uptake source was determined for maples and oaks using $\delta^{2} \mathrm{H}$ measured in transpiration from canopy leaves for each species $\left(\delta_{\mathrm{Tm}}=\right.$ maples, $\delta_{\mathrm{To}}=$ oaks; see section 4.2). Precipitation was collected at a nearby site in Zionsville, Indiana for DOY 241, 256, and 262. Precipitation $\delta^{2} \mathrm{H}$ values were $-30.46,-52.15$, and $-16.16 \%$, respectively (Tian and Wang, 2019). A soil isotope profile was established for US-MMS in 2018. $\delta^{2} \mathrm{H}$ values for sampled depths $(30 \mathrm{~cm}, 100 \mathrm{~cm}$, and $170 \mathrm{~cm})$ were $-45.30 \pm 0.07$ $\% o,-53.53 \pm 0.23 \%$, and $-115.12 \% \circ \pm 0.23$, respectively, matching the isotope gradient expected based on known fractionation processes. $\delta_{\text {To }}$ was consistently depleted, indicating that oaks did not use water from a near surface water source (Figure 2). Conversely, $\delta_{\mathrm{Tm}}$ varied throughout the study period, matching $\delta_{\mathrm{To}}$ on DOY 243, 248, and 269, and appearing significantly more enriched on DOY 250 and 271 (Figure 2). This means that maples at US-MMS are capable of accessing two unique soil water pools whereas oaks cannot.

Both increases in $\delta_{\mathrm{Tm}}$ occurred after rises in soil moisture as a result of a precipitation event, but the response time between soil moisture change and transpiration isotopic signal change was different. Precipitation on DOY 247 caused a rise in soil moisture which peaked on DOY 248 but began to rise before then, meaning it took $<1$ day for the precipitation to reach $30 \mathrm{~cm}$ deep (Figure 2). On DOY $248 \delta_{\mathrm{Tm}}$ was not statistically different than $\delta_{\mathrm{To}}$, however, on DOY $250, \delta_{\mathrm{Tm}}$ was significantly more enriched than $\delta_{\mathrm{To}}$, indicating that maples began using the newly percolated water (precipitation mixed with existing soil water) once it reached their root system and there is a slight lag from the start of a precipitation event to when a tree can access the new water. Because of the lag between the soil moisture sensor depth $(30 \mathrm{~cm})$ 
and the time at which maples were observed using water with a shallow signature, we can surmise that the rooting system of the maples was located deeper than $30 \mathrm{~cm}$ in the soil column (Figure 2).

The larger precipitation event on DOY 265 caused a similar rise in soil moisture, yet on DOY 269 $\delta_{\mathrm{Tm}}$ was not significantly different than $\delta_{\text {To }}$ despite sufficient time having passed for water to reach the root system of the maples. Two days later (DOY 271), $\delta_{\mathrm{Tm}}$ was significantly higher than $\delta_{\text {To }}$ just as observed earlier in the study period (DOY 248-250). This is somewhat surprising because the soil moisture on DOY 250 and 269 were both $\sim 20 \%$, thus it could be assumed that the water potential holding back the water was not substantially different between the two days. We expected maples to use the newly available shallow water source under such soil condition. An important factor here may the dramatically different atmospheric conditions on DOY 269 and 250. It may be possible for the higher VPD on DOY 269 (and the preceding days) to have caused maples to draw more water from their deeper root systems. Deeper root systems generally have larger conduit diameters (McElrone et al., 2004) and water conduction through the xylem increases to the fourth order of the conduit diameter (Poiseuille's Law), thus a sufficiently large increase in VPD could cause substantial water flow from deeper roots such that the shallow water contribution is reduced completely (lower or equal water potential to root xylem) or is too small compared to the volume brought from the deep roots. Midday LWP measurements on DOY 263, 264, and 269 were all lower than $-2 \mathrm{Mpa}$, which is remarkably low for A. sacharrum at USMMS and may be confounded by the time period of our measurements (Table S2, late growing season), or simply that maples can have fairly permeable cuticles (see Kerstiens, 1996; Lanning et al., 2020). In either case, the LWP measurements support our reasoning for the source water change because such a low value for a typically isohydric species (see Roman et al., 2015) may indicate a larger water supply. Consistent with this, the time series of isotopic measurements taken during the maple measurement period of DOY 269 showed that $\delta_{\mathrm{Tm}}$ decreased over the one-hour measurement period as VPD rose substantially (Figure S2, S3). This suggests increased contributions from a deeper water to the total water source for the maple over the one-hour measurement period. However, this pattern in sub-daily $\delta_{\mathrm{T}}$ may be normal and not explicitly due to quick onset atmospheric drought. Unfortunately, our measurements under such conditions and data on daily $\delta_{\mathrm{T}}$ values for maples and oaks are limited and measurements with better temporal resolutions are required for future studies.

Such observations are at odds with the common perceptions of which pools of water $Q$. alba and A. sacharrum access. At US-MMS, soil water availability for other trees has been inferred previously using predawn leaf water potential measurements (Roman et al., 2015; Yi et al., 2018). According to Yi et al. (2018), the predawn leaf water potential of $Q$. alba is lower than A. sacharrum under both moderate soil moisture ( $\mathrm{SWP} \geq-0.5 \mathrm{MPa}$ ) and water stressed conditions (SWP $<-0.5 \mathrm{MPa}$ ) indicating that oaks do 
not have access to a deeper soil water pool than A. sacharrum. However, our findings suggest that not only do $Q$. alba and A. sacharrum have deep water access, they may access the same subsurface pool (Figure 2). Under such circumstances, it seems possible that the difference in leaf water potential is not related to rooting depth but is physiological. However, it is also possible that the effect of drought length on deeper water stores could have played a role (reduced recharge). More generally, Quercus spp. are thought to be more deeply rooted than Acer spp., however, there may be some bias in that assumption, possibly linked to species level variations and the physical conditions of the basin they grow in. For instance, Matheny et al. (2016) reported isotopic measurements for cohabitating oaks (specifically $Q$. rubra) and maples (specifically A. rubrum) during the growing season at a northern Michigan Ameriflux site, US-UMB. Their data show overlap between the water source of both species at times, through there is clear separation for both species for most of the year (Matheny et al., 2016). Like US-MMS, it appears that the maples at US-UMB traverse water uptake depths while the oaks rely consistently on a deep water source. US-UMB is characterized by much sandier soils and deeper depth to bed rock than is observed at our measurement location in US-MMS (Curtis et al., 2005; Matheny et al., 2016; Schmid et al., 2000). The devotion of carbon resources to root growth for maples at US-UMB seems skewed towards opportunistic access to the ephemeral water pool in the upper soil profile. Whereas in US-MMS, isotopic evidence suggests maple root biomass is concentrated in two locations: one adapted for opportunistic shallow water use, and another devoted to long term accessibility of a stable deep water pool. It seems likely that the stability of water resources in both locations may influence the development of such root systems as water availability patterns in the subsurface would likely provide "incentive" to maintain root biomass in that area. However, the temporal resolutions of both Matheney et al. (2016) and this study are not sufficient to ascertain the annual dependence on discretized water pools. The overall importance of root carbon allocation, specifically in coarse roots, in surviving drought induced carbon starvation is significant (Kannenberg et al., 2017) and moving beyond a snapshot view into daily water sourcing for trees is an important area of future research.

\subsection{Leaf level processes}

Although maple transpiration and photosynthesis rates were significantly higher for the shallow water days than the deep water days (sans DOY 269, see section 4), these are likely due to higher VPD and higher intercellular $\mathrm{CO}_{2}$ on the shallow water days and not due to the water source itself (Figure 3). VPD was statistically higher on shallow water days $(\mathrm{p}<0.001)$ and was significantly correlated with the transpiration of maples $(\mathrm{r}=0.65, \mathrm{p}<0.001)$. Intercellular $\mathrm{CO}_{2}$ was also statistically higher on shallow water days $(\mathrm{p}<0.0001)$ and was significantly correlated with photosynthesis $(\mathrm{r}=0.46, \mathrm{p}<0.01)$. Observed patterns of $g_{s}, A$, and $T$ did not seem to be influenced by the location water was taken from 
(Figure 3). Due to these relationships it is hard to conclude that the difference in water source impacted the leaf physiology of maples, though more measurements under constant conditions would help confirm this.

\subsection{Experimental uncertainties}

Our interpretation of water uptake depth requires some scrutiny. The isotope composition of plant transpiration is the same as the water source used except for in a few cases of unique environments (e.g., high saline) or a particular species (e.g., Populus euphratica, see Zhao et al., 2016). We lack direct measurements of soil water isotopes at depth for our measurement days in 2017 which prevents a comparison to the exact soil values during the measurement period. Instead, we rely on measurements taken during the summer of 2018 and observed soil water isotopic distributions at other sites. Thus, a scenario could exist where our soil water isotopologue distribution became inverted during our measurement period, obscuring the uptake depth of the maples. For example, hydraulic redistribution could cause the isotopic signature of maple transpiration to look like a deeper water source even if the majority of soil water flux for maples came from a shallow location. During the day, water from deeper sources could move through their roots and be deposited in soils with water potentials lower than the xylem water potential upstream at night. Dawson (1996) reported this phenomenon in maples before, showing rises in soil moisture at night near large trees. This could cause the $\delta_{\mathrm{T}}$ of the following day to look like a mixture of deep and shallow sources. This would not change our conclusions as the 'deep water' days would simply be mixed water sources, taken from a shallow position in the soil column though contributed by two different water pools, heavily dominated by the deep water source. However, we do not observe any sustained increase in soil moisture at night greater than $0.1 \%$, eliminating hydraulic redistribution as a potential cause. More importantly, for hydraulic redistribution to explain our measured $\delta_{\mathrm{Tm}}$, it must still be possible for maples to draw from a deep water source as the surrounding species composition (ca. $10 \mathrm{~m}$ diameter) of the maples measured in this study are only other maples and understory species (predominantly spice bush, ca. $1 \mathrm{~m}$ tall), severely reducing the likelihood of other species redistributing the water. Dawson (1996) presented isotopic evidence showing marked differences in Acer sacharrum xylem water isotopes when comparing larger trees (more deeply rooted) to smaller tree (surface water reliant). The distinction in isotopic compositions paired with environmental and soil water does support our assumptions (following White et al., 1985) that Acer sacharrum does not fractionate its source water. This is different from other studies showing plants that fractionate heavy hydrogen isotopes when growing in unique environments (e.g., high saline or extremely dry environments) (e.g., Lin et al., 1993; Zhao et al., 2016). Additional analysis is still required from more species and wider environments to settle the plant water uptake fractionation issue. 
Another confounding factor on the interpretation of plant water sources is non-steady state (NSS) transpiration. Under steady state conditions $\delta_{\mathrm{T}}$ is equivalent to the isotopic composition of source water $\left(\delta_{\mathrm{S}}\right)$. Under NSS conditions, $\delta_{\mathrm{S}}$ is not equal to $\delta_{\mathrm{T}}$ because there is modification to the isotopic composition of the leaf water due to changes in environmental conditions (e.g., temperature, VPD), which results in variable transpiration and stomatal conductance. Given the large change in VPD over DOY 269 and the seemingly abnormal water use pattern of the maples on that day, it is possible that an NSS situation occurred and that may impact our results. However, it is noted that for all of our reported measurements we only utilized Keeling Plots which were linear. Doing so ensured that water vapor and isotope flux were occurring consistently with each other. A deviation from linearity would show that the isotope ratio and water vapor concentration were changing at different rates and thus we could not assume steady state conditions. We did not see this in our data, though it is possible that NSS effects would be apparent at longer timescales than our measurements were done at.

Due to sampling constraints our study species were sampled at different times of day (oaks $~ 9$ 11:30, maples 11:30 -15:00). Since maples were sampled during midday, we would expect those measurements to be impacted the least by NSS conditions. The oaks, however, were closer to a period when NSS effects are likely magnified (Farquhar and Cernusak, 2005). Despite this, oaks showed water sourcing and physiological behaviors consistent with other studies on the species (Figure 2,3; see Matheny et al., 2016). Based on this evidence, we do not think NSS conditions impacted our results or the interpretations of them. However, we acknowledge that we cannot completely rule out the possibility of NSS effect on $\delta_{\mathrm{T}}$ due to data constraints in our study.

\section{Concluding remarks}

Our results show that conventional assumptions about water resources available to maples are not universal over time or across locations. At US-MMS, the sampled maples do not exclusively take up water from the upper soil profile and can, in fact, draw water from the same source as oaks and this change in source is possibly driven by meteorology (i.e., high VPD) (Figures 4, S2). Additionally, taking water from deep or shallow sources had no direct effect on leaf function during our study period. Such findings have interesting implications for the greater plant physiology and hydrology communities.

The different responses to drought for cohabitating maples and oaks has been confounded by water accessibility. Although our observation period is short, we do present one of the first evaluations of water accessibility differences between species and their leaf level responses on a temporal scale, and perhaps one of the only direct measurements of plant transpiration isotopologues in the forest canopy. Soil moisture measurements in the top $30 \mathrm{~cm}$ have been used to describe soil moisture drought at many 
study sites across the world. In many locations, especially with shallow soils, this is likely sufficient to describe soil water status. However, for deeper soils, measurements at $30 \mathrm{~cm}$ may not accurately describe the subsurface water resources plants can access across all times of the year. According to previous definitions (see Roman et al., 2015) US-MMS was under drought conditions during our observation period. As discussed in section 1, previous studies at US-MMS have shown that the A, $\mathrm{g}_{\mathrm{s}}$, and T of oaks under similar conditions to be much higher than maples. We observed a similar pattern in our study (Figure 3). This suggests that the relative stomatal behaviors of maples and oaks may be physiological in origin and not exclusively due to subsurface water accessibility. Higher resolution measurements and more explicit inclusion of NSS calculations in future experiments would be useful in confirming this.

\section{Experimental section}

\subsection{Soil water isotopes}

Soil samples were collected from US-MMS in the summer of 2018 to confirm that the soil isotope composition distribution was consistent with other sites and with what is expected based on known fractionation patterns for this part of the United States. A soil pit was dug to bed rock $(\sim 2 \mathrm{~m})$ and samples were collected every $10 \mathrm{~cm}$. Water from samples at $30 \mathrm{~cm}, 100 \mathrm{~cm}$, and $170 \mathrm{~cm}$ was extracted using cryogenic distillation as per (West et al., 2006) and were analyzed using a Picarro L2130-I cavity ring-down spectrometer.

\subsection{Direct measurements of isotopic compositions of plant transpiration}

To obtain measurements of plant $\delta_{\mathrm{T}}$ we utilized a novel measuring method, which directly measures the isotope composition of plant transpiration from the tree canopy (Wang et al., 2012). A triple water vapor isotope analyzer (T-WVIA, Los Gatos Research) was lifted into the forest canopy at USMMS using a boom lift in the summer of 2017 (Figure 1D) and allowed to warm up for $30 \mathrm{~min}$. A single leaf (alive, dry, attached to the branch and free of insects), was placed into an acrylic leaf chamber (Figure 1C) attached to the T-WVIA by a short $(1.5 \mathrm{~m})$ Teflon tube. The leaf chamber had a port open to the atmosphere and also contained a fan (powered by an external battery) to prevent condensation and ensure mixing (Figure 1). Transpired water was drawn into the T-WVIA using an external pump set sufficiently high such that air was pulled through the chamber and into the T-WIA and not capable of exiting through the ambient air port (Figure 1A). All measurements were in sunny conditions between 0900 and 1500 hours with oaks sampled between $~ 9-11: 30$ and maples between 11:30-15:00 due to constraints in how the boomlift needed to be maneuvered at the sampling site. Each measurement was made on a different leaf with at least three replicates per tree ( $\mathrm{n}=2$ per species). 
The leaf remained in the chamber until the measured water concentration entering the T-WVIA plateaued (roughly $30-120 \mathrm{~s}$ ), at which point the leaf was removed from the chamber a few moments later. This step helped to ensure as near steady state conditions as possible, however, we acknowledge that non-steady state conditions are common in the field and may affect our isotope measurements (e.g., Dubbert et al., 2014). The chamber was then allowed to sit open to vent until the measured water concentration and isotope signature returned to stable ambient levels before another measurement was made to ensure all water taken into the T-WVIA left the vacuum chamber inside the instrument. It should be noted that 'ambient levels' are subjective as the canopy atmosphere is turbulent. We recommend a short waiting period prior to a measurement series to establish a 'baseline' for the ambient water vapor and isotope concentrations so that some reference can be established. This will help prevent and detect memory effects between samples. No leaf should be measured more than once. This measurement technique exposes the leaf to unique atmospheric conditions in the chamber (e.g., higher humidity and temperature) for long enough periods of time to induce stomatal closure which could severely bias the estimation of $\delta_{\mathrm{T}}$ if the measurement is repeated too frequently.

The Keeling Plot (KP) method was used to determine the $\delta_{\mathrm{T}}$ for each study species. KP were made by regressing the inverse water concentration and $\delta^{2} \mathrm{H}$ (Figure S4). The y-intercept of the least squares regression line indicates the $\delta_{\mathrm{T}}$ value for that measurement. For a perfect measurement resulting in a perfect KP, water concentrations and isotope concentrations increase linearly, and are correlated with a correlation coefficient greater than 0.9. However, in natural systems such consistency is not always possible. Using the chamber method, the measured water concentration will always increase linearly for an acceptable measurement and was thus used to define the measurement period during the data processing. The isotope concentration did not always increase linearly and could have variation throughout the measurement, possibly due to small variations in the ambient water vapor signature or due to unique parcels of water of varying isotope signatures passing through the stomata. Due to the variability of measurement times, each measurement period was defined and processed by hand with the aid of a script written in Matlab by the authors. To do this, the entire time period where the measured water concentration increased was isolated and considered the true measurement period. Any $\delta^{2} \mathrm{H}$ values outside two standard deviations of the mean were removed. To improve measurement usability, a 5 point moving average was generated for $1 /\left[\mathrm{H}_{2} \mathrm{O}\right]$ and $\delta^{2} \mathrm{H}$, which were then regressed (Figure S4). Comparisons between KP of the data before and after the moving average found no difference in y-intercepts larger than the measurement variability but did improve a few measurements such that our quality control parameters were met (Figure S4). Any regression with $\mathrm{R}^{2}<0.65$ was not included in the final analysis even if the y-intercept from that measurement matched a measurement of higher quality (e.g., $R^{2}=0.9$ ) for the same tree on the same day. The final estimates of $\delta_{\mathrm{T}}$ for a tree species on a given measurement day 
were compared using a Grubb's test to detect outliers which were then removed. One hundred total measurements were made on two canopy dominant Acer sacharrum and two canopy dominant Quercus alba over the study period of which 56 met our quality standards after processing. A standard deviation was not possible to calculate in one instance (DOY 243; Q. alba), otherwise, all $\delta_{\mathrm{T}}$ values reported include at least three replicates. Of the remaining 56 measurements, a subset was selected to check against a newer method of calculating $\delta_{\mathrm{T}}$ (Equation 3; see Good et al., 2012; Wang et al., 2012 for additional details) (Table S1). The period used for ambient vapor concentration $\left(\mathrm{C}_{\mathrm{A}}\right)$ and isotopic composition $\left(\delta_{\mathrm{A}}\right)$ were the approximately 1-2 minutes prior to the leaf chamber measurement and the period for mixed vapor concentration $\left(\mathrm{C}_{\mathrm{M}}\right)$ and isotopic composition $\left(\delta_{\mathrm{M}}\right)$ were the same as used for the KP method. Within the optimal concentration range of the instrument, both methods obtain the same results, however, at higher water vapor concentrations there is a significant offset between calculated $\delta_{\mathrm{T}}$ values. Additionally, on DOY 296, $C_{A}$ was less stable, possibly magnifying the difference in results between the methods. This will not likely impact our data interpretation because the difference was consistent between species.

$$
\delta_{T}=\frac{C_{M} \delta_{M}-C_{A} \delta_{A}}{C_{M}-C_{A}}
$$

Throughout the measurement period, the T-WVIA was calibrated using a Water Vapor Isotope Standard Source (WVISS, Los Gatos Research) which generates a vapor composition of a known isotopic value which was plumbed into the T-WVIA. The T-WVIA and WVISS were connected via a heated Teflon tube to prevent condensation. The standard operating procedure was followed as described by (Tian et al., 2016). Data quality using the Off-Axis Integrated Cavity Output Spectroscopy (OA-ICOS) technique on which the T-WVIA functions is based is inherently biased based on water concentration (Tian et al., 2016). We calibrated the T-WVIA four times surrounding the measurement period across a range of different water concentrations $(10,000 \mathrm{ppm}-25,000 \mathrm{ppm})$ using an isotope standard closest to our measured values (Los Gatos Research, 3C) to ensure data accuracy under all measurement conditions that would be experienced in the leaf chamber. Data was calibrated by fitting a linear regression across water concentrations and applying a correction factor. The instrument also drifted linearly across the measurement period. Correction factors for sampled days were interpolated from the regression equation establish between the days added to the uncalibrated value recorded by the instrument (Fiorella et al., 2018; Tian et al., 2016).

4.3 Eddy covariance and leaf level measurements

Fluxes of water, $\mathrm{CO}_{2}$, and energy were measured using a 3D sonic anemometer (CSAT-3; Campbell Scientific, Logan, UT, USA) and a closed path infrared gas analyzer (LI-7000, Li-Cor, Lincoln, NE, USA) recorded at a frequency of $10 \mathrm{~Hz}$. Data for the study period were processed using standard post 
processing described in (Dragoni et al., 2011; Schmid et al., 2000). Soil moisture measurements were taken from the soil moisture monitoring station nearest our study trees (TDR1; CS615 and CS616, Campbell Scientific).

Transpiration rates $(\mathrm{T})$, stomatal conductance $\left(\mathrm{g}_{\mathrm{s}}\right)$, and photosynthesis $(\mathrm{A})$ were measured in maples and oaks using a portable photosynthesis system (LI-6400XT, Li-Cor, Lincoln, NE) at the same time as the isotopic measurements were made. Canopy meteorological conditions (e.g., air temperature, VPD) were also recorded in tandem with the leaf measurements. All measurements were made on the same region of the tree, however, no leaf measured using the LI-6400XT was used for isotopic measurements and vice versa as discussed in section 4.2. The measurements of $\mathrm{T}, \mathrm{g}_{\mathrm{s}}$, and A for maples and oaks were compared across days using a one-way ANOVA, to elucidate the role of deep water use on leave level function (Figure 3). Additionally, measurements of $\mathrm{T}, \mathrm{g}_{\mathrm{s}}$, and A for maples were binned by water source (sans DOY 269) and compared using a two-sample $t$ test and linear regression analysis to evaluate broader patterns and minimize day to day variations.

Leaf water potential measurements were made using a Scholander-type pressure system (PMS Instruments, Corvallis, OR). Leaves were cut from the canopy sampling locations and inserted into the pressure chamber. Dinitrogen gas was added until water was visible on the petiole of the leaf.

\section{Acknowledgments}

The authors would like to express their immense gratitude for the help and dedication of Steve Scott and Michael Voyles. This project would not have been possible without their assistance in instrument calibration, data collection and measurement, as well as boomlift operation over the duration of the experiment. We would also like to acknowledge Chao Tian, Paula Robert, and Derek Gibson for their in lab assistance with cryogenic soil extractions and isotope analysis, as well as Caralynne Shaffer for illustrating the boomlift in Figure 1. We acknowledge support from the Agriculture and Food Research Initiative program (grant number: 201767013-26191) of the USDA National Institute of Food and Agriculture. We would like to thank two anonymous reviewers and Prof. Guillaume Tcherkez for their constructive comments, which significantly improved the quality of this manuscript. 


\section{References}

Abrams, M.D., 1990. Adaptations and responses to drought in Quercus species of North America. Tree Physiol.

Bowen, G.J., Wilkinson, B., 2002. Spatial distribution of $\{$ delta $\} 180$ in meteoric precipitation. Geology 30, 315-318. https://doi.org/10.1130/0091-7613(2002)030<0315:sdooim>2.0.co;2

Curtis, P.S., Vogel, C.S., Gough, C.M., Schmid, H.P., Su, H.B., Bovard, B.D., 2005. Respiratory carbon losses and the carbon-use efficiency of a northern hardwood forest, 1999-2003. New Phytol. 167, 437-456. https://doi.org/10.1111/j.1469-8137.2005.01438.x

Dawson, T.E., 1996. Determining water use by trees and forests from isotopic, energy balance and transpiration analyses: the roles of tree size and hydraulic lift. Tree Physiol. 16, 263-272. https://doi.org/10.1093/treephys/16.1-2.263

Dawson, T.E., Ehleringer, J.R., 1993. Isotopic enrichment of water in the "woody" tissues of plants: implications for plant water source, water uptake, and other studies which use the stable isotopic composition of cellulose. Geochim. Cosmochim. Acta 57, 3487-3492.

Dragoni, D., Schmid, H.P., Wayson, C.A., Potter, H., Grimmond, C.S.B., Randolph, J.C., 2011. Evidence of increased net ecosystem productivity associated with a longer vegetated season in a deciduous forest in south central Indiana, USA. Glob. Chang. Biol. 17, 886-897.

Dubbert, M., Cuntz, M., Piayda, A., Werner, C., 2014. Oxygen isotope signatures of transpired water vapor: The role of isotopic non-steady-state transpiration under natural conditions. New Phytol. 203, 1242-1252. https://doi.org/10.1111/nph.12878

Farquhar, G.D., Cernusak, L.A., 2005. On the isotopic composition of leaf water in the non-steady state. Funct. Plant Biol. 32, 293-303, doi:10.1071/FP04232.

Fiorella, R.P., Poulsen, C.J., Matheny, A.M., 2018. Seasonal Patterns of Water Cycling in a Deep, Continental Mountain Valley Inferred From Stable Water Vapor Isotopes. J. Geophys. Res. Atmos. 123, 7271-7291. https://doi.org/10.1029/2017JD028093

Gaines, K.P., Stanley, J.W., Meinzer, F.C., McCulloh, K.A., Woodruff, D.R., Chen, W., Adams, T.S., Lin, H., Eissenstat, D.M., 2016. Reliance on shallow soil water in a mixed-hardwood forest in central Pennsylvania. Tree Physiol. 36, 444-458. https://doi.org/10.1093/treephys/tpv113

Good, S.P., Soderberg, K., Wang, L., Caylor, K.K., 2012. Uncertainties in the assessment of the isotopic 
composition of surface fluxes: A direct comparison of techniques using laser-based water vapor isotope analyzers. J. Geophys. Res. 117, D15301. https://doi.org/10.1029/2011JD017168

Jasechko, S., Sharp, Z.D., Gibson, J.J., Birks, S.J., Yi, Y., Fawcett, P.J., 2013. Terrestrial water fluxes dominated by transpiration. Nature 496, 347-350. https://doi.org/10.1038/nature11983

Kannenberg, S.A., Novick, K.A., Phillips, R.P., 2017. Coarse roots prevent declines in whole-tree nonstructural carbohydrate pools during drought in an isohydric and an anisohydric species. Tree Physiol. 1-9. https://doi.org/10.1093/treephys/tpx119

Kaseke, K.F., Wang, L., Seely, M., 2017. Nonrainfall water origins and formation mechanisms. Sci. Adv. 3. https://doi.org/10.1126/sciadv.1603131

Kaseke, K.F., Wang, L., Wanke, H., Turewicz, V., Koeniger, P., 2016. An analysis of precipitation isotope distributions across Namibia using historical data. PLoS One 11, e0154598. https://doi.org/10.1371/journal.pone.0154598

Kerstiens, G., 1996. Cuticular water permeability and its physiological significance. J. Exp. Bot. 47, 1813-1832. https://doi.org/10.1093/jxb/47.12.1813

Klein, T., 2014. The variability of stomatal sensitivity to leaf water potential across tree species indicates a continuum between isohydric and anisohydric behaviours. Funct. Ecol. 28, 1313-1320. https://doi.org/10.1111/1365-2435.12289

Lanning, M., Wang, L., Novick, K.A., 2020. The importance of cuticular permeance in assessing plant water - use strategies. Tree Physiol. 1-8. https://doi.org/10.1093/treephys/tpaa020

Lanning, M., Wang, L., Scanlon, T.M., Vadeboncoeur, M.A., Adams, M.B., Epstein, H.E., Druckenbrod, D., 2019. Intensified vegetation water use under acid deposition. Sci. Adv. 5, eaav5168. https://doi.org/10.1126/sciadv.aav5168

Lin, G.H., Sternberg, L., Ehleringer, J.R., Hall, A.E., Farquhar, G.D., 1993. Hydrogen isotopic fractionation by plant roots during water uptake in coastal wetland plants, in: Stable Isotopes and Plant Carbon-Water Relations. Academic Press Inc., pp. 497-510.

Lu, X., Liang, L.L., Wang, L., Jenerette, G.D., McCabe, M.F., Grantz, D.A., 2017. Partitioning of evapotranspiration using a stable isotope technique in an arid and high temperature agricultural production system. Agric. Water Manag. https://doi.org/10.1016/j.agwat.2016.08.012

Martinez-Vilalta, J., Poyatos, R., Aguade, D., Retana, J., Mencuccini, M., 2014. A new look at water 
transport regulation in plants. New Phytol. 204, 105-115. https://doi.org/10.1111/nph.12912

Matheny, A.M., Fiorella, R.P., Bohrer, G., Poulsen, C.J., Morin, T.H., Wunderlich, A., Vogel, C.S., Curtis, P.S., 2016. Contrasting strategies of hydraulic control in two codominant temperate tree species. Ecohydrology 10, e1815. https://doi.org/10.1002/eco.1815

Oerter, E., Finstad, K., Schaefer, J., Goldsmith, G.R., Dawson, T., Amundson, R., 2014. Oxygen isotope fractionation effects in soil water via interaction with cations ( $\mathrm{Mg}, \mathrm{Ca}, \mathrm{K}, \mathrm{Na}$ ) adsorbed to phyllosilicate clay minerals. J. Hydrol. 515, 1-9. https://doi.org/10.1016/j.jhydrol.2014.04.029

Oren, R., Sperry, J., Katul, G., Pataki, D., Ewers, B., Phillips, N., Schäfer, K., 1999. Survey and synthesis of intra-and interspecific variation in stomatal sensitivity to vapour pressure deficit. Plant. Cell Environ. 22, 1515-1526. https://doi.org/10.1046/j.1365-3040.1999.00513.x

Roman, D.T., Novick, K.A., Brzostek, E.R., Dragoni, D., Rahman, F., Phillips, R.P., 2015. The role of isohydric and anisohydric species in determining ecosystem-scale response to severe drought. Oecologia 179, 641-654. https://doi.org/10.1007/s00442-015-3380-9

Schlesinger, W.H., Jasechko, S., 2014. Transpiration in the global water cycle. Agric. For. Meteorol. 189190, 115-117. https://doi.org/http://dx.doi.org/10.1016/j.agrformet.2014.01.011

Schmid, H.P., Grimmond, C.S.B., Cropley, F., Offerle, B., Su, H.-B., 2000. Measurements of CO2 and energy fluxes over a mixed hardwood forest in the midwestern United States. Agric. For. Meteorol. $103,355-373$.

Simonin, K.A., Roddy, A.B., Link, P., Apodaca, R., Tu, K.P., Hu, J., Dawson, T.E., Barbour, M.M., 2013. Isotopic composition of transpiration and rates of change in leaf water isotopologue storage in response to environmental variables. Plant. Cell Environ. 36, 2190-2206.

Tardieu, F., Lafarge, T., Simonneau, T., 1996. Stomatal control by fed or endogenous xylem ABA in sunflower: Interpretation of correlations between leaf water potential and stomatal conductance in anisohydric species. Plant, Cell Environ. 19, 75-84. https://doi.org/10.1111/j.1365-

3040.1996.tb00228.x

Thomsen, J.E., Bohrer, G., Matheny, A.M., Ivanov, V.Y., He, L., Renninger, H.J., Schäfer, K.V.R., 2013. Contrasting hydraulic strategies during dry soil conditions in Quercus rubra and Acer rubrum in a sandy site in Michigan. Forests 4, 1106-1120. https://doi.org/10.3390/f4041106

Tian, C., Wang, L., 2019. Data descriptor: Stable isotope variations of daily precipitation from 20142018 in the central United States. Sci. Data 6, 1-8. https://doi.org/10.1038/sdata.2019.18 
Tian, C., Wang, L., Kaseke, K.F., Bird, B.W., 2018. Stable isotope compositions ( $\delta 2 H, \delta 18 O$ and $\delta 17 O)$ of rainfall and snowfall in the central United States. Sci. Rep. 8, 1-15.

https://doi.org/10.1038/s41598-018-25102-7

Tian, C., Wang, L., Novick, K.A., 2016. Water vapor $\delta 2 \mathrm{H}, \delta 18 \mathrm{O}$ and $\delta 17 \mathrm{O}$ measurements using an offaxis integrated cavity output spectrometer - sensitivity to water vapor concentration, delta value and averaging-time. Rapid Commun. Mass Spectrom. 30, 2077-2086. https://doi.org/10.1002/rcm.7714

Wang, L., Good, S.P., Caylor, K.K., 2014. Global synthesis of vegetation control on evapotranspiration partitioning. Geophys. Res. Lett. 41, 1-5. https://doi.org/10.1002/2014GL061439

Wang, L., Good, S.P., Caylor, K.K., Cernusak, L.A., 2012. Direct quantification of leaf transpiration isotopic composition. Agric. For. Meteorol. 154-155, 127-135. https://doi.org/http://dx.doi.org/10.1016/j.agrformet.2011.10.018

West, A.G., Patrickson, S.J., Ehleringer, J.R., 2006. Water extraction times for plant and soil materials used in stable isotope analysis. Rapid Commun. Mass Spectrom. 20, 1317-1321. https://doi.org/10.1002/rcm.2456 Water

White, J.W.C., Cook, E.R., Lawrence, J.R., Broecker, W.S., 1985. The D/H ratios of sap in trees: implications for water sources and tree ring D/H ratios. Geochim. Cosmochim. 49, 237-246. https://doi.org/10.1016/0016-7037(85)90207-8

Yi, K., Dragoni, D., Phillips, R.P., Roman, D.T., Novick, K.A., 2017. Dynamics of stem water uptake among isohydric and anisohydric species experiencing a severe drought. Tree Physiol. 37, 13791392. https://doi.org/10.1093/treephys/tpw126

Yi, K., Maxwell, J.T., Wenzel, M.K., Roman, D.T., Sauer, P.E., Phillips, R.P., Novick, K.A., 2018. Linking variation in intrinsic water-use efficiency to isohydricity: a comparison at multiple spatiotemporal scales. New Phytol. 221, 195-208. https://doi.org/10.1111/nph.15384

Zhao, L., Xiao, H., Zhou, M., Cheng, G., Wang, L., Yin, L., Ren, J. (2012). Factors controlling spatial and seasonal distributions of precipitation $\delta^{18} \mathrm{O}$ in China. Hydrological Processes 26, 143-152.

Zhao, L., Wang, L., Cernusak, L.A., Liu, X., Xiao, H., Zhou, M., Zhang, S., 2016. Significant difference in hydrogen isotope composition between xylem and tissue water in Populus euphratica. Plant. Cell Environ. 39, 1848-1857. https://doi.org/10.1111/pce.12753

Zimmermann, U., Ehhalt, D., Münnich, K.O., 1967. Soil-water movement and evapotranspiration: Changes in the isotopic composition of the water. Symp. Isot. Hydrol. I, 567-585. 


\section{Figure legends}

Figure 1. Graphical representation (A) and field photos (B-D) of the equipment used to measure the stable isotopic composition of plant transpiration. The labeled items in panel A are as follows: 1. Triple water vapor isotope analyzer, 2. External pump, 3. Leaf chamber, 4. Flow path of air in the system. For more details, please reference section 4 .

Figure 2. Fluctuations in vapor pressure deficit (VPD), soil moisture (soil moisture), and transpiration isotope signatures $\left(\delta_{\mathrm{T}}\right)$ for maples $\left(\delta_{\mathrm{Tm}}\right)$ and oaks $\left(\delta_{\mathrm{To}}\right)$ displayed with precipitation amounts for each day of the study period (2017). Error bars shown are 1 standard deviation of the mean.

Figure 3. Leaf level measurements of assimilation (A), stomatal conductance ( $\left.g_{s}\right)$, and transpiration $(T)$ of maples and oaks. Species were compared using a one-way ANOVA, significance was set to 0.05 and denoted using the letters placed above the box plots. The right hand panels are frequency distribution plots of measured A, $g_{s}$, and T for maples and oaks on DOY 243, 248, 250, 269, and 271 of 2017.

Figure 4. A diagram summarizing the soil water isotope gradient and water source utilization for maples and oaks during the study period. Arrow size indicates the relative contribution of each soil water pool to the isotopic composition of canopy transpiration. 

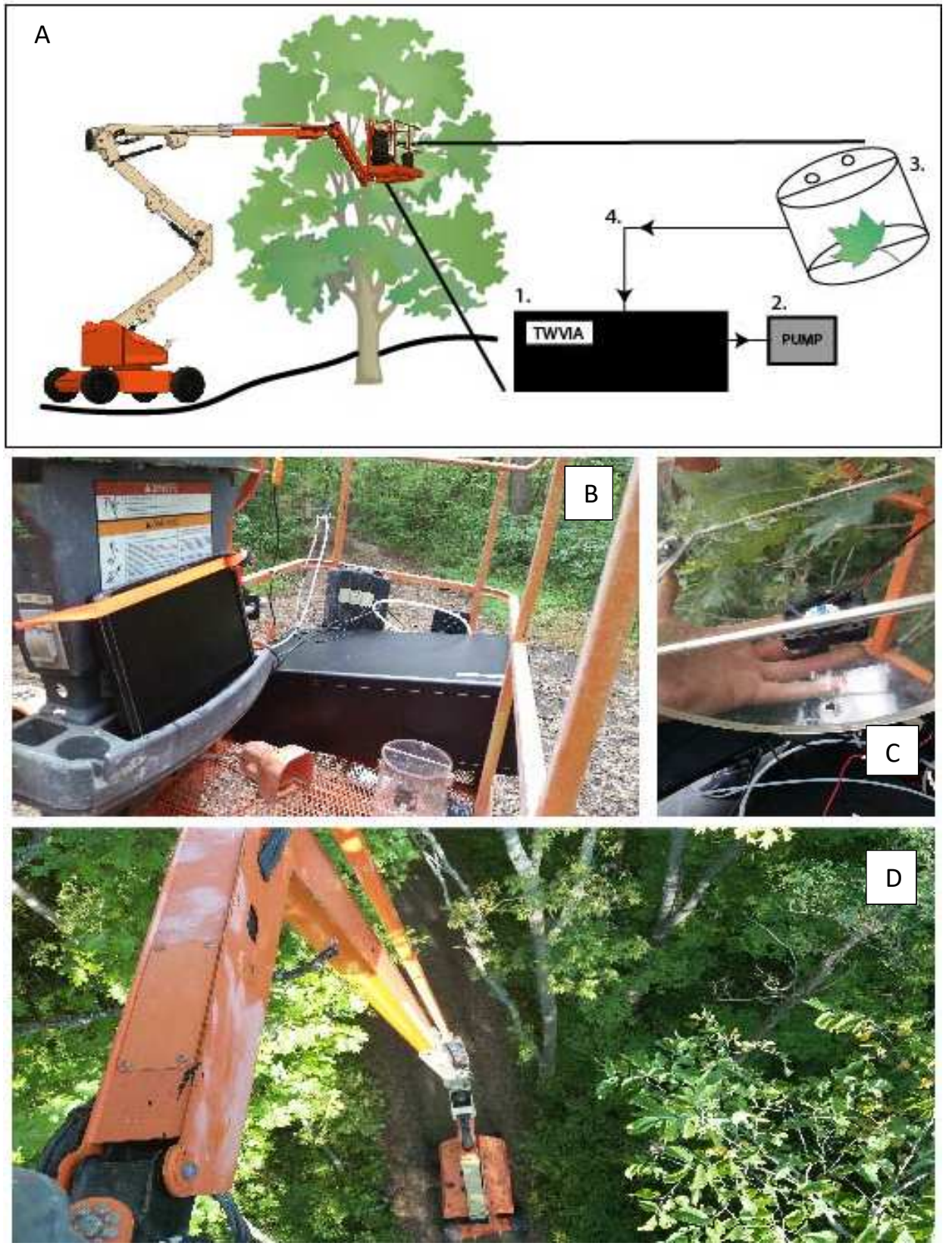

Figure 1. 


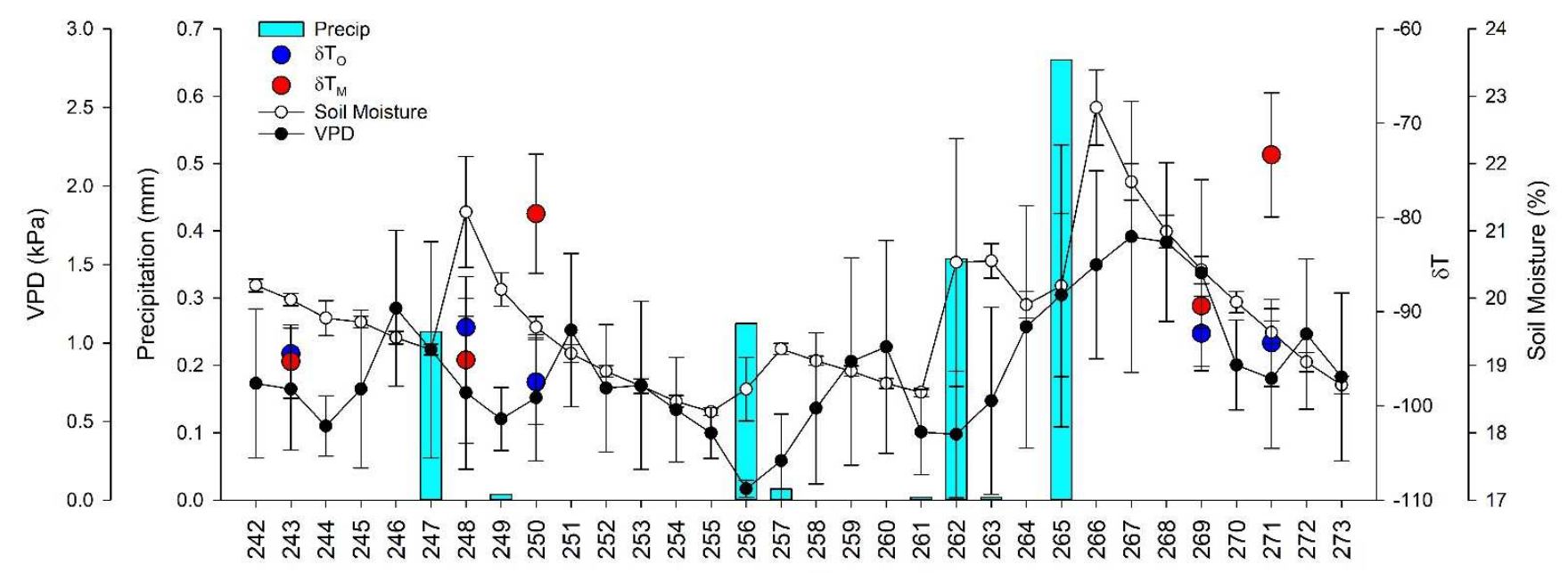

Day of Year (DOY)

Figure 2. 

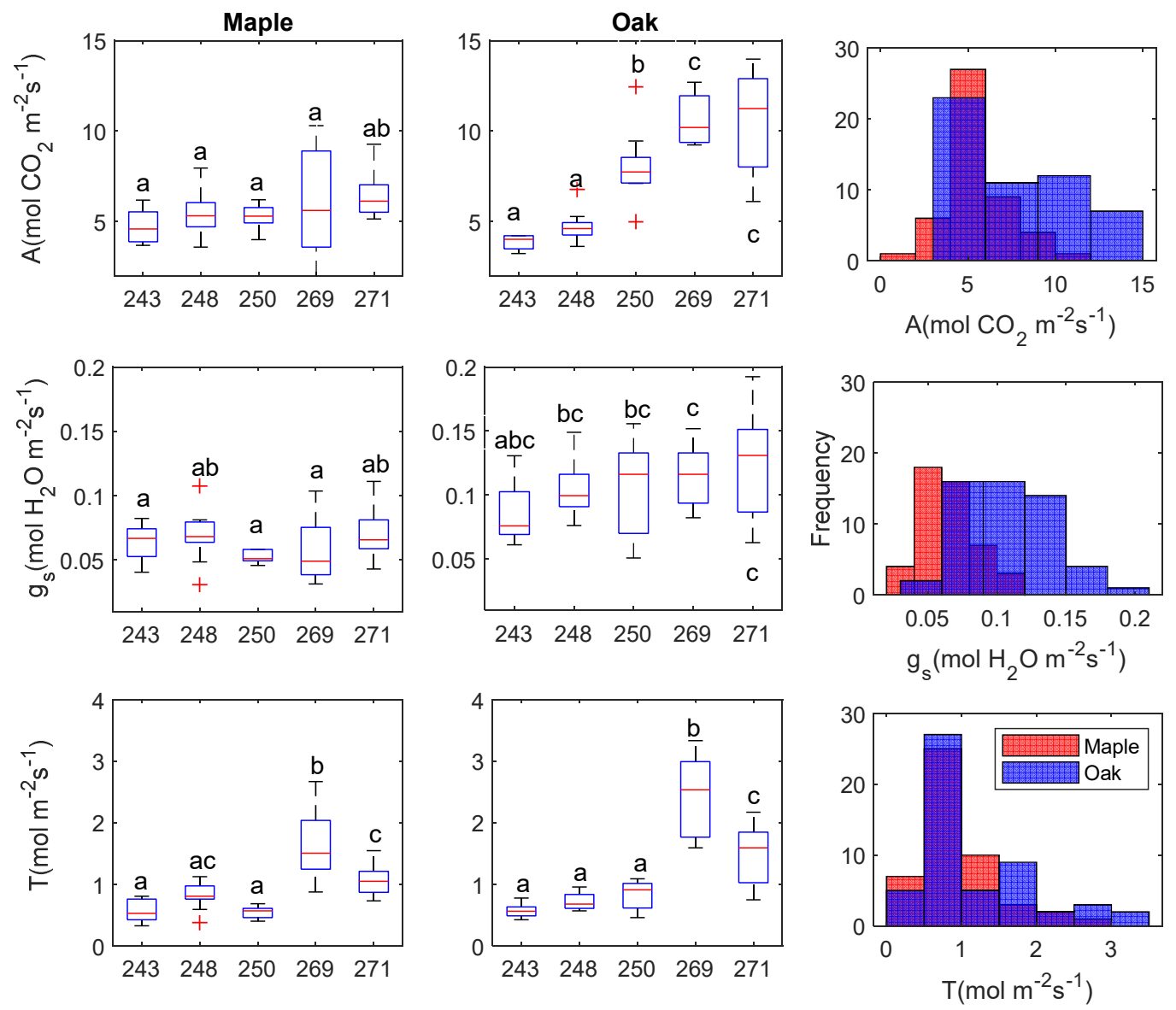

Figure 3. 


\section{Acer sacharrum}

The water source accessed by maples may be dependent on new precipitation and merterological factors.

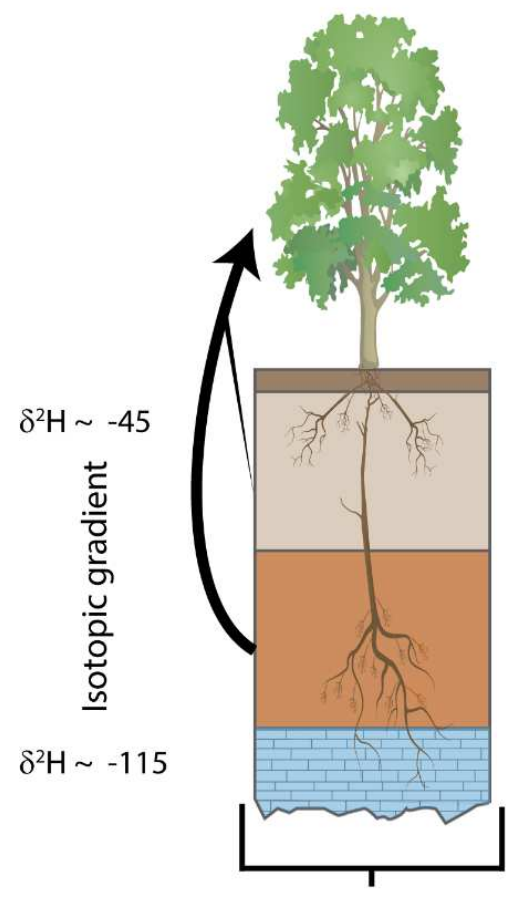

Deep water source utilization

was previously uassociated with maples.

Deep water can be utilized over

shallow moisture sources if the vapor pressure deficit is suffeciently high.

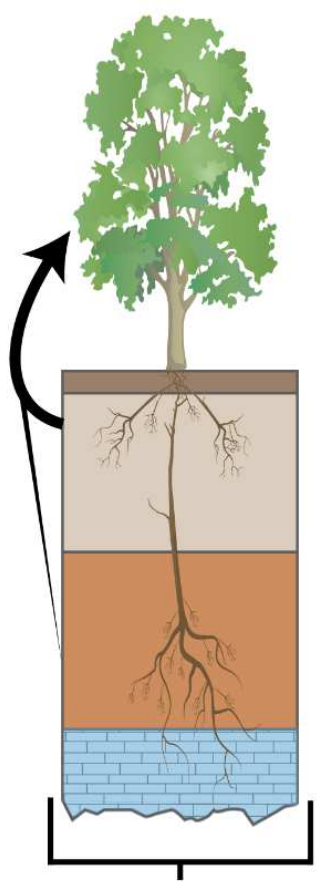

Shallow water utilization

comes days after precipitation event, which indicates maples use the new wate once it reaches the roots. It is utilized even

if deep moisture is avalible.

\section{Quercus alba}

Oaks utilize only deep water sources and do not switch due to new precipitation or high VPD.

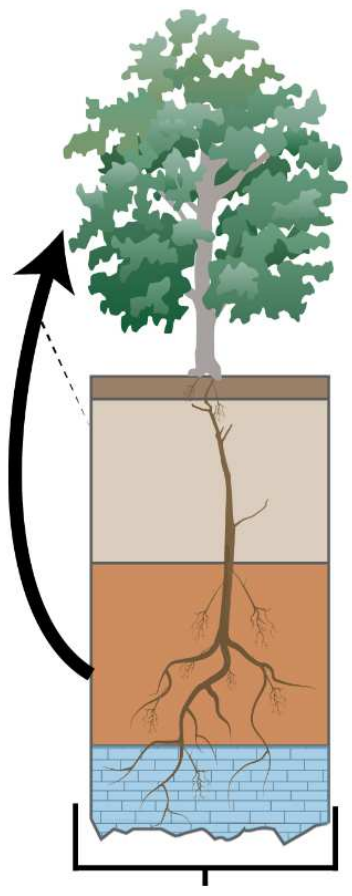

Daily isotope signature of the oaks reflects a deeper water pool and is not distingushable from the deep water source utilized by the maples.

\section{Figure 4.}


Canopy isotopic investigation reveals different water uptake dynamics of maples and oaks

Matthew Lanning ${ }^{1}$, Lixin Wang ${ }^{1 *}$, Michael Benson ${ }^{2}$, Quan Zhang ${ }^{3}$, Kimberly A. Novick ${ }^{2}$

${ }^{1}$ Department of Earth Science, Indiana University-Purdue University Indianapolis, 723 West Michigan Street, Indianapolis, IN 46202, USA

${ }^{2}$ School of Public and Environmental Affairs, Indiana University Bloomington, 1315 East Tenth Street, Bloomington, IN 47405, USA

${ }^{3}$ State Key Laboratory of Water Resources and Hydropower Engineering Science, Wuhan University, Wuhan 430072, China

* Correspondence to:

Lixin Wang (lxwang@iupui.edu)

Department of Earth Sciences

Indiana University-Purdue University Indianapolis

Indianapolis, IN 46202, USA

Office phone number: 317-274-7764 

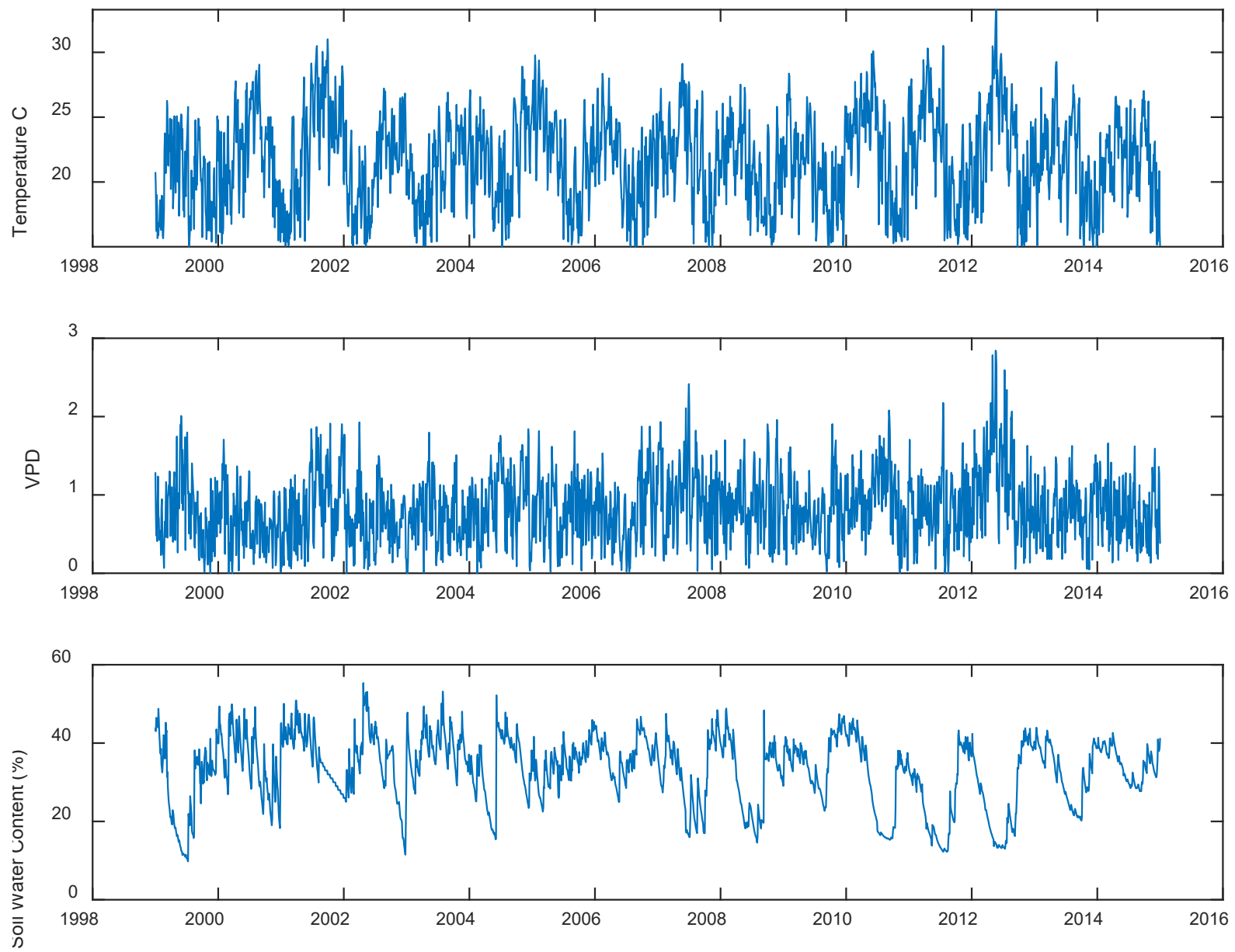

Figure S1. Historical temperature, vapor pressure deficit (VPD), and soil water content for the US-MMS flux site. This data is part of the FLUXNET 2015 data product and is available for download via the FLUXNET site. 


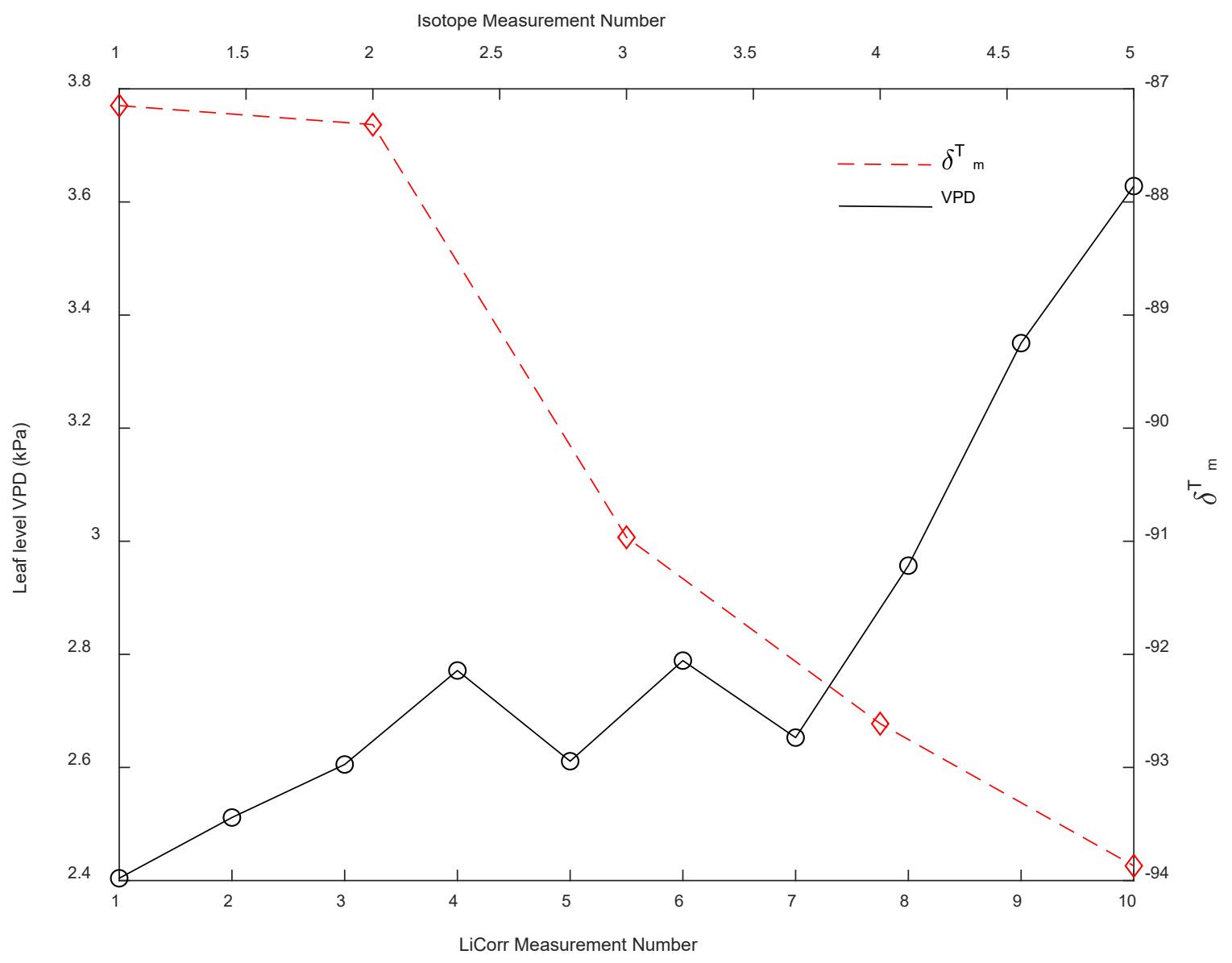

Figure S2. Changes in leaf level VPD and $\delta$ Tm on DOY 269 during a one-hour measurement window. Measurements were taken from two trees with canopies which intercepted one another. 

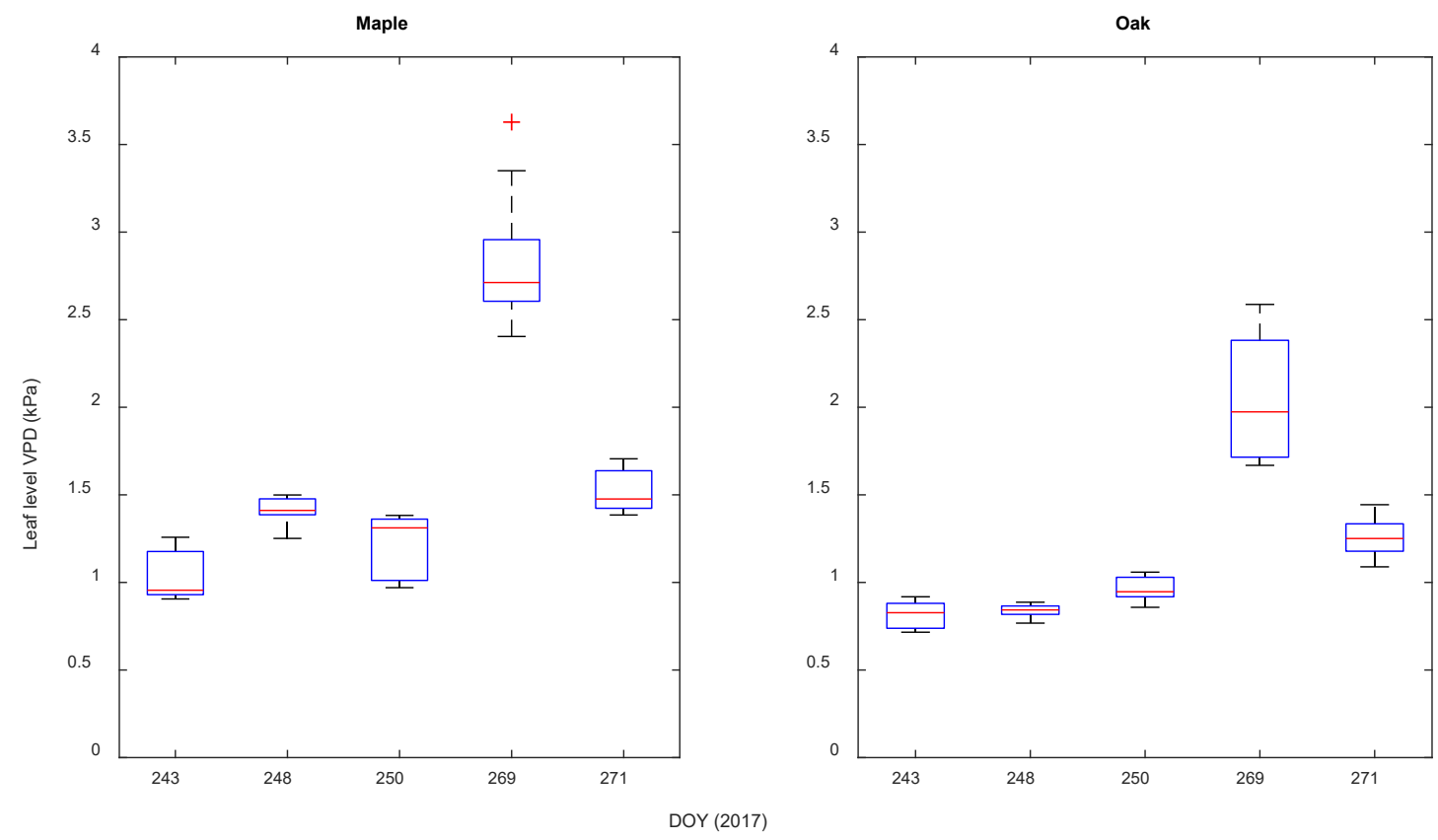

Figure S3. Daily leaf level VPD for maples and oaks measured using a LiCorr 6400 during the measurement period. 


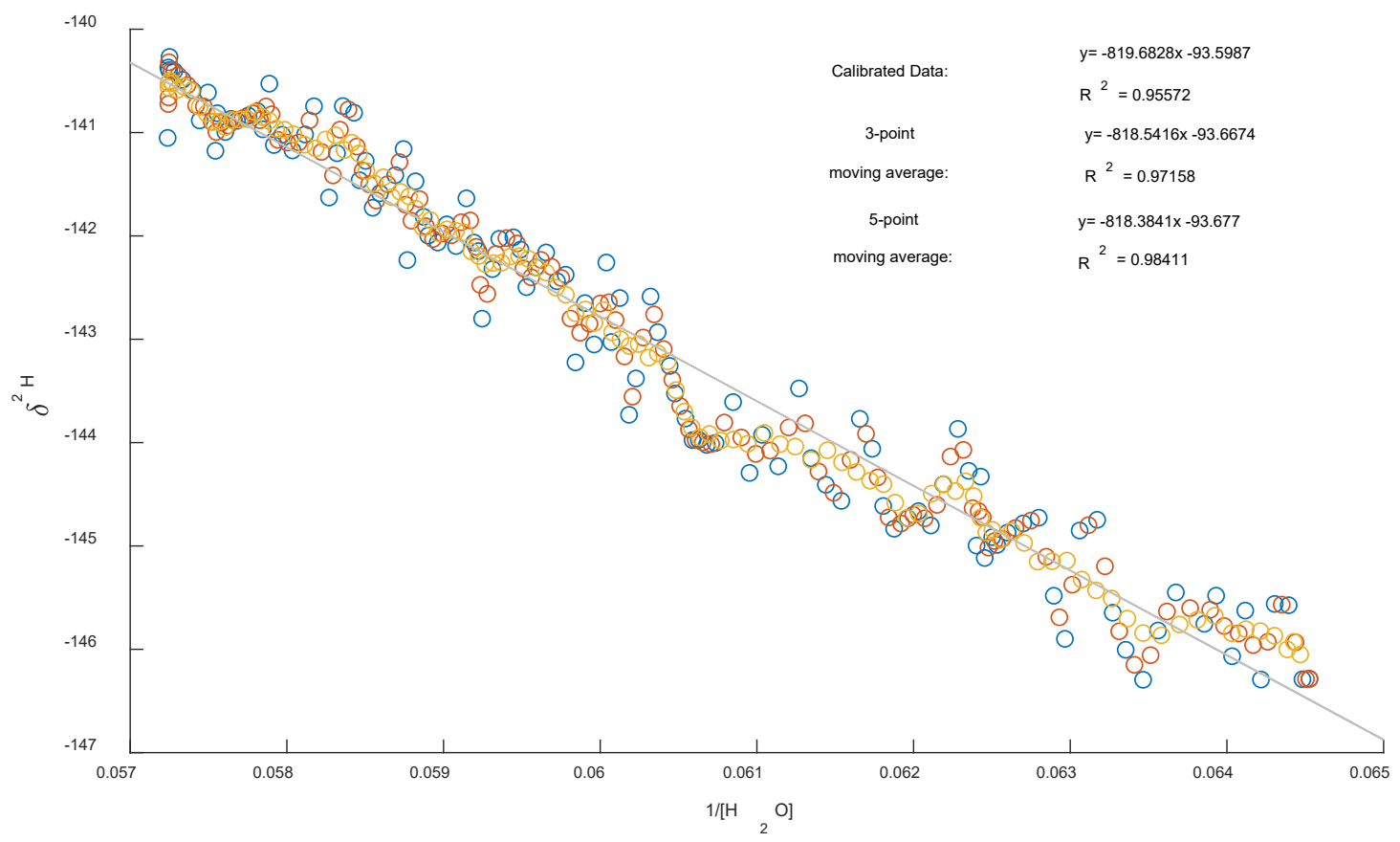

Figure S4. A Keeling plot example with original data (blue), 3 point (orange), and 5 point (yellow) moving averages applied as well as line equations and regression statistics for each, top to bottom, respectively. 
Table S1. Comparison of two methods of calculating $\delta_{\mathrm{T}}$ on an individual leaf sample under diverse conditions for both maples and oaks.

\begin{tabular}{|c|c|c|c|c|c|}
\hline Date & $D O Y$ & Species & $\begin{array}{c}\text { Keeling } \\
\text { Plot }\end{array}$ & $\begin{array}{c}\text { Mass } \\
\text { Balance }\end{array}$ & Daily $\delta_{T} S D$ \\
\hline \multirow[t]{2}{*}{$9 / 5 / 2017$} & 249 & Maple & -80.06 & -80.61 & 8.85 \\
\hline & & Oak & -93.68 & -97.36 & 3.09 \\
\hline \multirow[t]{2}{*}{$9 / 26 / 2017$} & 269 & Maple & -87.31 & -95.02 & 2.74 \\
\hline & & Oak & -86.41 & -94.40 & 4.28 \\
\hline
\end{tabular}


Table S2. Leaf water potential (LWP) measurements taken at the time of isotope sampling during the summer of 2017.

\begin{tabular}{c|rr}
\multicolumn{2}{c}{$L W P(M P a)$} \\
\hline$D O Y$ & Q. alba & A. sacharrum \\
\hline 243 & -1.88 & Not measured \\
248 & -1.52 & -0.82 \\
250 & -1.60 & -0.84 \\
269 & -2.23 & -2.19 \\
271 & -2.04 & -1.88
\end{tabular}

